\title{
Log10 Colony Forming Units per Gram
}

National Cancer Institute

\section{Source}

National Cancer Institute. Log 10 Colony Forming Units per Gram. NCI Thesaurus. Code C102658.

A log arithmic-scale (base 10) unit for measuring colony forming units per unit of mass equal to one gram. 